\title{
Erratum to: Using nonparametric conditional approach to integrate quality into efficiency analysis: empirical evidence from cardiology departments
}

\author{
Yauheniya Varabyova $^{1}$ • Carl Rudolf Blankart ${ }^{1,2}$ • Jonas Schreyögg ${ }^{1}$
}

Published online: 13 February 2017

(C) Springer Science+Business Media New York 2017

Erratum to: Health Care Manag Sci

DOI:10.1007/s10729-016-9372-4

Due to a technical error, the PDF version of the article contains an error in the explanation to Formula (2.2), below the said formula. The HTML version of the article bears the correct format and is provided below as well.

where $\hat{S}_{Y \mid X, Z}(y \mid x, z)=\frac{\sum_{i=1}^{n} \mathrm{I}\left(x_{i} \leq x, y_{i} \geq y\right) K\left(\left(z-z_{i}\right) / h_{n}\right)}{\sum_{i=1}^{n} \mathrm{I}\left(x_{i} \leq x\right) K\left(\left(z-z_{i}\right) / h_{n}\right)}$

The online version of the original article can be found at http://dx.doi. org/10.1007/s10729-016-9372-4

\footnotetext{
Yauheniya Varabyova

yauheniya.varabyova@uni-hamburg.de

1 Hamburg Center for Health Economics, Universität Hamburg,

Esplanade 36, 20354 Hamburg, Germany

2 Center for Gerontology and Health Care Research, School of Public Health, Brown University, Providence, RI, USA
} 